\title{
Sol-Gel Transition of Branched Low Density Polyethylene in Organic Solvents
}

\author{
Hideomi Matsuda, Mitsuhiro Imaizumi, Hitoshi Fujimatsu, \\ Shigetaka KUROIWA, and Masaru OKABE* \\ Department of Chemical Engineering, Faculty of Textile Science, \\ Shinshu University, 3-15-1, Tokida, Ueda 386, Japan \\ * Department of Chemical Process Engineering, Faculty of Engineering, \\ Ikutoku Technical University, Atsugi, Kanagawa 243-02, Japan
}

(Received October 7, 1983)

\begin{abstract}
The sol-gel transition of branched low density polyethylenes in decalin, tetralin, $o$-xylene, toluene and benzene was studied. Gel-melting temperatures increased with polymer concentration. Experimental data were analyzed by the theory proposed by Takahashi, Sakai, and Kato for the gel-melting temperature of branched polymers. Our data adhered closely to the theory by which the size of a crystalline junction in the gel could be estimated.

KEY WORDS Sol-Gel Transition / Gel / Gel-Melting Temperature / Polyethylene / Branched Polyethylene / Low Density Polyethylene /
\end{abstract}

In our previous papers, ${ }^{1,2}$ solutions of branched low density polyethylene in cyclohexane and carbon disulfide mixed solvents were shown to be converted to gels on cooling and that each such gel reverted to a solution on warming at near room temperature. The gelmelting temperature depended on the molecular weight of the polymer and solution concentration. At about that time, Takahashi, Sakai, and $\mathrm{Kato}^{3}$ proposed a theory for treating the gel-melting temperature of a branched polymer gel. This theory is useful for determining molecular weight dependence of the gelmelting temperature and estimating the size of a crystalline junction point in the gel. We applied this theory to gel-melting temperatures for a series of fractionated branched low density polyethylenes in cyclohexane and carbon disulfide mixed solvents. ${ }^{4}$ Recently, Barbam, Hill and Keller ${ }^{5}$ reported that a dilute solution of polyethylene in xylene was converted to gel on cooling, after it had been stirred at an elevated temperature. We also reported that solutions of branched low density polyethylene in decalin, tetralin and $o$-xylene were converted to thermo-reversible gels on cooling. ${ }^{6}$

These facts indicate that the sol-gel transition of branched low density polyethylene in organic solvents is a general property of the polymer.

In this paper, sol-gel transitions of branched low density polyethylene in decalin, tetralin, $o$ xylene, toluene and benzene were studied and the experimental data obtained were analyzed by the theory of Takahashi, Sakai and Kato.

\section{EXPERIMENTAL}

\section{Materials}

The four samples used of unfractionated branched low density polyethylene were supplied and characterized by Motegi of the Ohita Laboratory, Showa Denko Co. Their typical physical properties are shown in Table I.

The samples, S-11, S-12, and S-14 had nearly equal numbers of branches per 1000 carbon atoms, but their molecular weights differed. The molecular weight and branching degree of 
Table I. Physical properties of branched low density polyethylenes ${ }^{\mathrm{a}}$

\begin{tabular}{lcrrr}
\hline & Density & & & \\
Sample & $M_{w} \times 10^{-4}$ & $\mathrm{CH}_{3} / 1000 \mathrm{C}$ & {$[\eta]$} \\
\cline { 5 - 5 } & $\mathrm{g} \mathrm{cm}^{-3}$ & $(\mathrm{GPC})$ & (IR) & $100 \mathrm{~cm}^{3} \mathrm{~g}^{-1}$ \\
\hline S-11 & 0.921 & 7.4 & 24.2 & 0.875 \\
S-12 & 0.920 & 16.1 & 25.8 & 1.137 \\
S-14 & 0.923 & 13.7 & 24.2 & 1.099 \\
S-16 & 0.917 & 17.5 & 30.4 & 1.070 \\
\hline
\end{tabular}

a $M_{w}$, weight-average molecular weight obtained by GPC; $\mathrm{CH}_{3} / 1000 \mathrm{C}$, the number of methyl groups per 1000 carbon atoms determined by infrared analysis; $[\eta]$, measured in tetralin at $130^{\circ} \mathrm{C}$.
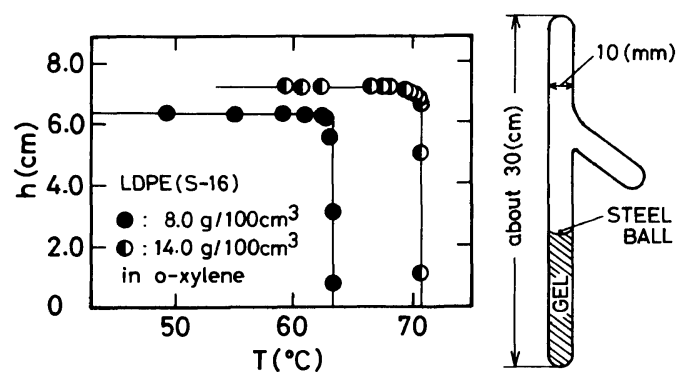

Figure 1. Gel-melting temperature apparatus and examples of gel-melting measurement.

S-16 were the largest among the samples examined. Each sample was dissolved in xylene at its boiling temperature, precipitated into cooled methanol, and dried under reduced pressure.

Decalin, tetralin, $o$-xylene, toluene and benzene were purified before use by ordinary methods.

\section{Measurement of Gel-Melting Temperature}

Gel-melting temperature was measured by the method proposed by Takahashi, Sakai and $\mathrm{Kato}^{3}$; for details, reference should be made to their papers. ${ }^{3,6}$ The apparatus for gel-melting temperature measurement is shown in Figure 1. A definite sample weight and a volume of the solvent were placed in the apparatus which was then sealed. A steel ball about $30 \mathrm{mg}$ in weight was placed in the arm of the apparatus. The polymer was dissolved completely at $110^{\circ} \mathrm{C}$. After the solution had been maintained at room temperature for $10 \mathrm{~min}$, the apparatus was immersed for $24 \mathrm{~h}$ in a thermobath regulated at $10^{\circ} \mathrm{C}$. During this process, the polymer did not precipitate and the solution turned into a gel. The steel ball was then moved to the top of the gel by a magnet, and the gel was warmed at a rate of $6^{\circ} \mathrm{Ch}^{-1}$. The height $h$ of the steel ball from a reference level was measured by a cathetometer at selected temperatures. On melting, the steel ball began to fall. Typical changes in $\mathrm{h}$ with temperature are shown in Figure 1. The temperature at which the horizontal and vertical straight lines intersected was defined as the gel-melting temperature. As in our previous study, ${ }^{6}$ the dependence of the gel-melting temperature on the weight of the steel ball was examined prior to a series of experiments, and the steel ball was chosen on this basis.

\section{Measurement of Swelling Ratio}

To analyze our experimental results by the theory proposed by Takahashi, Sakai and $\mathrm{Kato}^{3}$ the interaction energy densities for the polymer-solvent pairs were estimated by measurement of the swelling ratio. $0.1 \mathrm{~g}$ of a branched low density polyethylene sample (density, $0.920 \mathrm{~g} \mathrm{~cm}^{-3}$ at $25^{\circ} \mathrm{C}$ and numberaverage molecular weight $M_{n}, 1.76 \times 10^{4}$ ) was moulded into films which were then $60 \mathrm{Mrad}$ irradiated by an electron beam so as to crosslink the polymer molecules. Soluble parts of the films were extracted by xylene at its boiling point for $24 \mathrm{~h}$. The crosslinked films were dried and their weights were determined. The crosslinked films were swollen in $p$-xylene for $24 \mathrm{~h}$ at $72.7^{\circ} \mathrm{C}$, the swelling ratio determined, and the volume fraction of polymer $\phi_{2}$ in the swollen film calculated. The molecular weight $M_{\mathrm{c}}$ between crosslinking points was calculated from ${ }^{3}$

$$
M_{\mathrm{c}}=\frac{M_{n} d v_{1}\left(\phi_{2}{ }^{1 / 3}-2 \phi_{2} / v\right)}{2 d v_{1}\left(\phi_{2}{ }^{1 / 3}-2 \phi_{2} / v\right)-M_{n}\left[\ln \left(1-\phi_{2}\right)+\phi_{2}+\chi_{1} \phi_{2}{ }^{2}\right]}
$$


where $d$ is the density of the film, $v_{1}$, the molar volume of the solvent, $M_{n}$, the number-average molecular weight of the sample before crosslinking, $v$, the functionality of a crosslinked point, and $\chi_{1}$, the Flory-Huggins interaction parameter.

With $v=3$ and $\chi_{1}=0.511$ for the polyethylene $+p$-xylene system, ${ }^{7} M_{\mathrm{c}}$ was determined to be $8.0 \times 10^{3}-8.6 \times 10^{3}$. Identical films were swollen in respective solvents at $40^{\circ} \mathrm{C}$ for $24 \mathrm{~h}$ and the swelling ratios determined. The $\chi_{1}$ parameters for branched low density polyethylene in these solvents were calculated by eq 1 with this value of $M_{\mathrm{c}}$.

\section{RESULTS AND DISCUSSION}

Solutions of branched low density polyethylene in decalin, tetralin, $o$-xylene, toluene and benzene were converted to thermoreversible gels on cooling. The gel-melting temperature increased with polymer concentration. The relation between gel-melting temperature and polymer concentration in decalin is illustrated in Figure 2. Similar relations were obtained in other solvents. In dilute solutions, no thermo-reversible gel was formed, but the polymer precipitated from the solution on cooling.

Eldridge and Ferry ${ }^{8}$ proposed the following empirical relation between gel-melting temperature $T_{\mathrm{m}}^{\mathrm{g}}$ and volume fraction $v_{2}$ of poly-

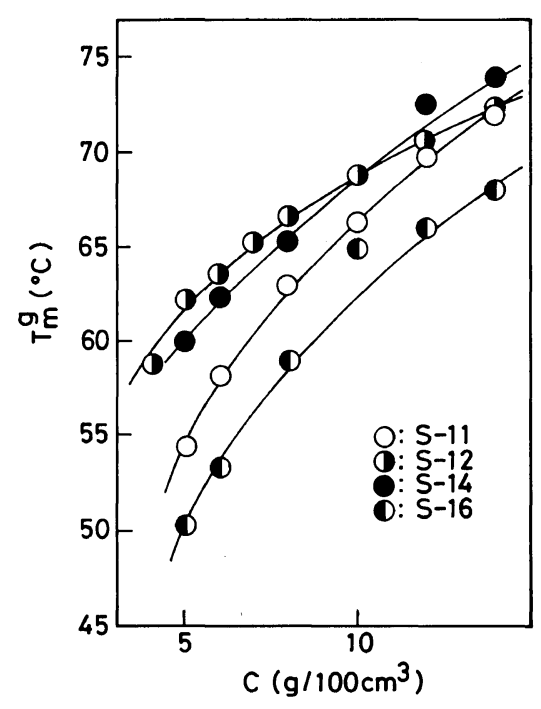

Figure 2. Relation between gel-melting temperature and concentration for branched low density polyethylenes in decalin.

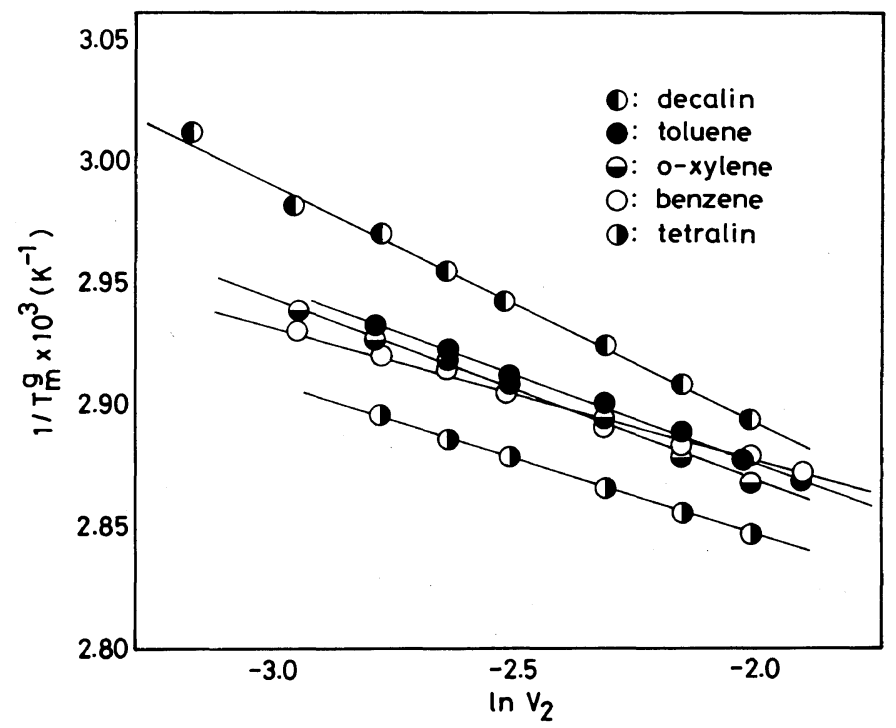

Figure 3. Relation between the reciprocal of gel-melting temperature and the logarithm of polymer concentration for S-12. 
mer in the gel,

$$
\ln v_{2}=\text { const. }+\Delta H_{\mathrm{m}} / T_{\mathrm{m}}^{\mathrm{g}}
$$

where $\Delta H_{\mathrm{m}}$ is the heat absorbed on formation of one mol of junction points. Eldridge and Ferry's plots for S-12 are illustrated in Figure 3 which indicates that Eldridge and Ferry's relation was obeyed for all solvent studied. Similar relations were obtained for other samples. However, the mechanism of gelation and dependence of the gel-melting temperature on molecular weight or branching degree could not be elucidated by this type of plot, being merely empirical.

Branched low density polyethylene has long chain branches and thus the theory of Takahashi, Sakai and Kato, which assumes a copolymeric character of branched polymers, ${ }^{3}$ is applicable to our data. According to this theory, the following equation can be derived assuming that branched polyethylene is an $f$ star branched polymer:

$$
\begin{aligned}
\frac{1}{T_{\mathrm{m}}{ }^{9}}= & \frac{\zeta}{\zeta \Delta h_{\mathrm{u}}+\zeta B^{\prime} V_{\mathrm{A}}-2 \sigma_{\mathrm{ec}}} \\
& \times\left(\frac{\Delta h_{\mathrm{u}}}{T_{\mathrm{m}}{ }^{0}}+\frac{R V_{\mathrm{A}}}{V_{1}}-R \ln X_{\mathrm{A}}\right) \\
& -\frac{R}{\rho\left(\zeta \Delta h_{\mathrm{u}}+\zeta B^{\prime} V_{\mathrm{A}}-2 \sigma_{\mathrm{ec}}\right)} \\
& \times\left\{\ln M_{w}+(\rho-1) \ln v_{2}\right. \\
& +\ln \rho[\rho(f-1)-1]\}
\end{aligned}
$$

where $\zeta$ and $\rho$ are the ethylene-unit length and number of crystalline sequences in a crystallite, respectively, $\Delta h_{\mathrm{u}}$, the heat of fusion of an ethylene unit, $B^{\prime}$, the cohesive energy density defined by $\chi_{1}=B^{\prime} V_{1} / R T, \sigma_{\mathrm{ec}}$, the end interfacial free energy per crystalline sequence, $T_{\mathrm{m}}{ }^{0}$, the melting temperature of linear polyethylene, $X_{\mathrm{A}}$, the mole fraction of crystalline units, and $V_{\mathrm{A}}$ and $V_{1}$, the molar volume of a crystalline unit and the solvent, respectively. When the values of parameters other than $\rho$ and $\zeta$ in eq 3 are known, $\rho$ and $\zeta$ can be estimated from gel-melting temperature data
Table II. Parameters values for branched low density polyethylene ${ }^{3}$

\begin{tabular}{lc}
\hline$\sigma_{\mathrm{ec}}$ & $2840 \mathrm{cal} \mathrm{mol}^{-1}$ \\
$\Delta h_{\mathrm{u}}$ & $1920 \mathrm{cal} \mathrm{mol}^{-1}$ \\
$T_{\mathrm{m}}^{\mathrm{m}}$ & $418.6 \mathrm{~K}$ \\
$V_{\mathrm{A}}$ & $28 \mathrm{~cm}^{3} \mathrm{~mol}^{-1}$ \\
\hline
\end{tabular}

Table III. Estimated values of $V_{1}$ and $B^{\prime}$

\begin{tabular}{lccc}
\hline & \multicolumn{1}{c}{$V_{1}$} & $B^{\prime}$ \\
\cline { 2 - 3 } Solvent & $\mathrm{cm}^{3} \mathrm{~mol}^{-1}$ & & $\mathrm{cal} \mathrm{cm}^{-3}$ \\
& 158.6 & 2.41 \\
Decalin & 137.9 & 3.48 \\
Tetralin & 123.0 & 3.60 \\
$o$-Xylene & 106.2 & 3.81 \\
Toluene & 91.0 & 4.91 \\
Benzene & & \\
\hline
\end{tabular}

Table IV. Molecular parameters values for branched low density polyethylenes

\begin{tabular}{ccccc}
\hline Sample & $M_{w} \times 10^{-4}$ & $\lambda M_{w}$ & $f$ & $X_{\mathrm{A}}$ \\
\hline S-11 & 7.4 & 2.9 & 5 & 0.976 \\
S-12 & 16.1 & 6.8 & 9 & 0.974 \\
S-14 & 13.7 & 5.6 & 8 & 0.976 \\
S-16 & 17.5 & 8.9 & 11 & 0.970 \\
\hline
\end{tabular}

as follows. Assuming an appropriate value for $\rho$, we plot $1 / T_{\mathrm{m}}{ }^{\mathrm{g}}$ against $\ln M_{w}+(\rho-1) \ln v_{2}+$ $\ln \rho[\rho(f-1)-1]$ and determine the intercept and slope of the plot. Then we can calculate $\zeta$ and $\rho$ from the resulting values. This calculation is repeated until the assumed and calculated $\rho$ values coincide. Among the parameters of eq $3, \sigma_{\text {ec }}, \Delta h_{\mathrm{u}}, T_{\mathrm{m}}{ }^{0}$ and $V_{\mathrm{A}}$ are characteristic of branched low density polyethylene, and hence the values proposed by Takahashi, Sakai and $\mathrm{Kato}^{3}$ (shown in Table II) were conveniently used. The molar volumes $V_{1}$ were calculated from the densities of the solvents, and the cohesive energy densities $B^{\prime}$ were determined by measuring the swelling ratios of the polymer in the respective solvents with results presented in Table III. The mole fraction $V_{\mathrm{A}}$ of crystalline units was calculated from 


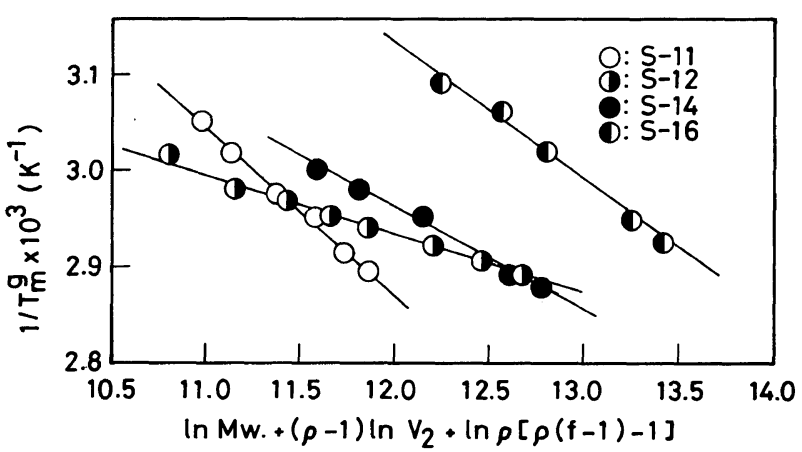

Figure 4. Relation between the reciprocal of gel-melting temperature and $\ln M_{w}+(\rho-1) \ln v_{2}+\ln \rho[\rho(f-1)-1]$ in decalin.

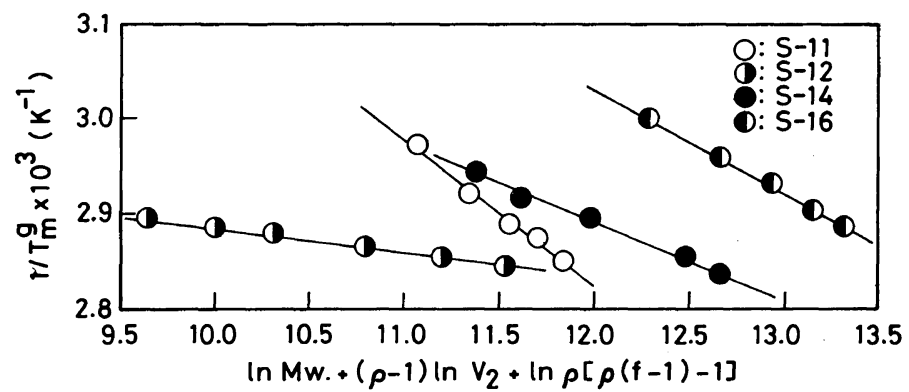

Figure 5. Relation between the reciprocal of gel-melting temperature and $\ln M_{w}+(\rho-1) \ln v_{2}+\ln \rho[\rho(f-1)-1]$ in tetralin.

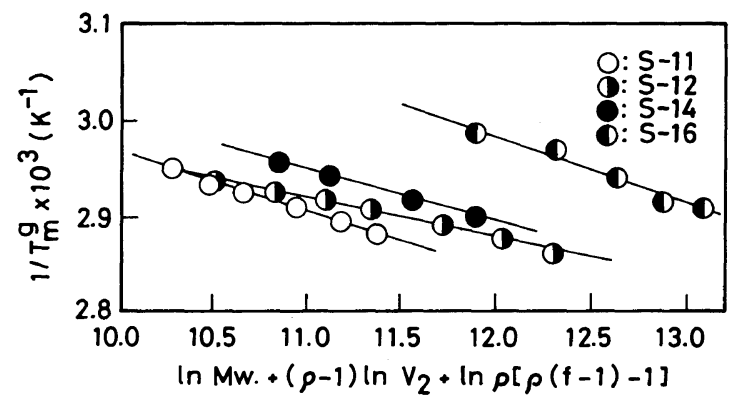

Figure 6. Relation between the reciprocal of gel-melting temperature and $\ln M_{w}+(\rho-1) \ln v_{2}+\ln \rho[\rho(f-1)-1]$ in $o$-xylene.

$V_{\mathrm{A}}=\left[1-0.001\left(\mathrm{CH}_{3} / 1000 \mathrm{C}\right)\right]$, where $\mathrm{CH}_{3} /$ $1000 \mathrm{C}$ is the number of methyl groups per 1000 carbon atoms. ${ }^{3} f$ was taken to be $\lambda M_{w}+2$, where $\lambda$ is the branch density. ${ }^{3}$ The values of $\lambda$ were calculated by the ZimmStockmayer method $^{9}$ using the procedure presented in the previous paper. ${ }^{4}$ The molecular parameters so obtained for branched low density polyethylenes are summarized in Table IV.

The results derived by applying the above method to our experimental data are shown in Figures $4-8$, and the calculated values of $\rho$ and $\zeta$ are summarized in Table V. It can be seen that the theory of Takahashi, Sakai and Kato is well applicable to the sol-gel transition 
of branched low density polyethylene in a cyclohexane + carbon disulfide mixed solvent as well as in decalin, tetralin, $o$-xylene, toluene and benzene. It is likely that $\rho$ and $\zeta$ are independent of the molecular weight, the number of branches per 1000 carbon atoms of the polymer and the solvent. In our previous paper, ${ }^{4}$ we showed that $\rho$ and $\zeta$ were independent of the molecular weight of the polymer. The present results support the findings in previous study. However, the dependence of $\rho$ and $\zeta$ on the branch degree could not be shown in the present study, since the branch degree of the sample did not vary systematically. Moreover, the values of $\rho$ were too small to form crystalline nuclei in the gels. Our values of $\rho$ and $\zeta$ should be compared with the values derived by other methods such as Xray diffraction. This will be carried out at some future date.

In conclusion, the present study clarified the

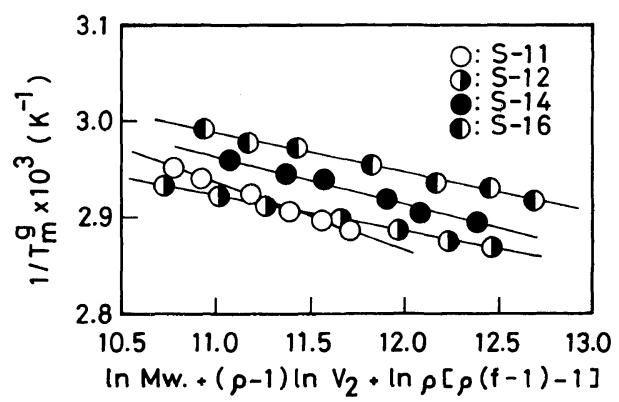

Figure 7. Relation between the reciprocal of gelmelting temperature and $\ln M_{w}+(\rho-1) \ln v_{2}+\ln \rho[\rho(f-1)-1]$ in toluene. following facts for the sol-gel transition of branched low density polyethylene in organic solvents. This polymer in decalin, tetralin, $O$ xylene, toluene and benzene is converted to a thermo-reversible gel on cooling. The gelmelting temperature depends on the polymer concentration and molecular weight, and its reciprocal varies linearly with the logarithm of

Table V. Estimated values of $\rho$ and $\zeta$

\begin{tabular}{cccr}
\hline $\begin{array}{c}\text { Sample } \\
\text { (LDPE) }\end{array}$ & Solvent & $\rho$ & $\zeta$ \\
\hline S-11 & o-Xylene & 2.4 & 9.6 \\
S-12 & & 2.9 & 11.3 \\
S-14 & & 2.6 & 9.7 \\
S-16 & & 2.5 & 8.2 \\
S-11 & Tetralin & 2.0 & 6.1 \\
S-12 & & 3.5 & 13.7 \\
S-14 & & 2.4 & 8.0 \\
S-16 & & 2.3 & 6.6 \\
S-11 & Decalin & 2.0 & 5.8 \\
S-12 & & 2.6 & 9.2 \\
S-14 & & 2.3 & 7.1 \\
S-16 & & 2.3 & 5.9 \\
S-11 & Toluene & 2.3 & 8.8 \\
S-12 & & 2.9 & 12.1 \\
S-14 & & 2.6 & 9.9 \\
S-16 & & 3.0 & 11.1 \\
S-11 & Benzene & 2.4 & 10.2 \\
S-12 & & 3.6 & 10.2 \\
S-14 & & 2.8 & 11.3 \\
S-16 & & 3.5 & 13.0 \\
\hline
\end{tabular}

a $\rho$, crystalline sequence of crystallites.

b $\zeta$, ethylene-unit length of crystallite.

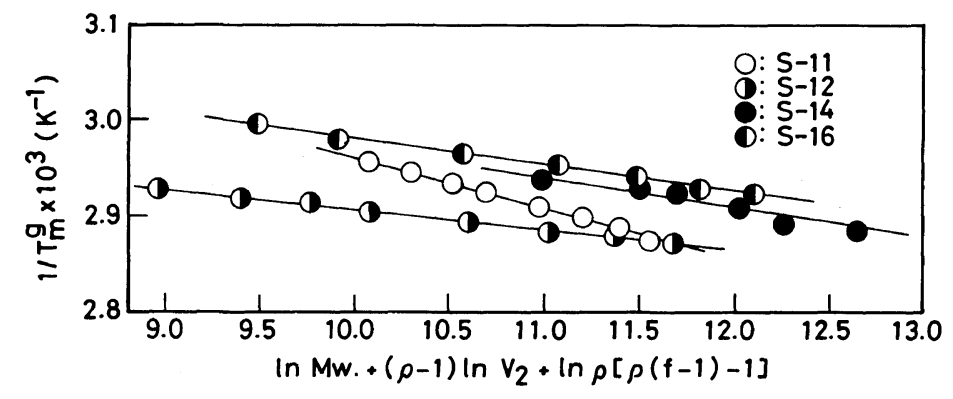

Figure 8. Relation between the reciprocal of gel-melting temperature and $\ln M_{w}+(\rho-1) \ln v_{2}+\ln \rho[\rho(f-1)-1]$ in benzene. 
the polymer concentration. The theory of Takahashi, Sakai and Kato is quite applicable to the systems studied, and allows calculation of the size of a crystalline junction in the gel. The sizes obtained in different solvents are nearly equal and independent of the molecular weight of the polymer.

Acknowledgement. The authors wish to express their sincere appreciation to $\mathrm{Mr}$. Yoshihiro Motegi of the Ohita Laboratory, Showa Denko Co. for supplying the samples and making their characterization. Thanks are also due to Dr. Toshio Shigematsu of Ibaragi Electrocommunication Laboratory, Nippon Telegraph and Telephone Corporation for irradiating the polymers with an electron beam. One of us (H. Matsuda) is grateful to Showa Denko Co. for a grant by which this work was possible. Partial support was also obtained through a Grant-in-Aid from the Ministry of Education.

\section{REFERENCES}

1. H. Matsuda, K. Araki, M. Yamada, and S. Kuroiwa, Rep. Prog. Polym. Phys. Jpn., 20, 69 (1977).

2. H. Matsuda and S. Kuroiwa, Rep. Prog. Polym. Phys. Jpn., 22, 45 (1979).

3. A. Takahashi, M. Sakai, and T. Kato, Polym. J., 12, 335 (1980).

4. H. Matsuda, K. Araki, H. Fujimatsu, and S. Kuroiwa, Polym. J., 13, 587 (1981).

5. P. J. Barbam, M. J. Hill, and A. Keller, Kolloid Z. Z. Polym., 258, 899 (1980).

6. H. Matsuda, H. Fujimatsu, M. Imaizumi, and S. Kuroiwa, Polym. J., 13, 807 (1981).

7. M. S. Muthan and H. Mark, J. Polym. Sci., 4, 527 (1949).

8. J. E. Eldridge and J. D. Ferry, J. Phys. Chem., 58, 992 (1954).

9. B. H. Zimm and W. H. Stockmayer, J. Chem. Phys., 12, 1301 (1949). 